\title{
Craniometric Measurements of New Zealand Rabbits Skull from Three- Dimensional Reconstruction Images
}

\author{
Sema Özkadif ${ }^{*}$, Emrullah Eken $^{2}$ \\ ${ }^{1}$ Batman University, School of Health, Department of Nursing, Batman/ Turkey \\ semaerten80@gmail.com \\ ${ }^{2}$ Selçuk University, Faculty of Veterinary Medicine, Department of Anatomy, Konya/ Turkey \\ eeken@selcuk.edu.tr
}

\begin{abstract}
This study aims to find out the differences between sexes on basis of craniometric measurements obtained from 3-dimensional (3D) reconstruction of multidetector computed tomography (MDCT) images in New Zealand rabbits. For this purpose, 12 adult healthy New Zealand rabbits of both sexes were used as materials. After MDCT images of the skulls were taken, they evaluated in a personel computer and reconstructed 3-dimensionally with the $3 D$ translator component of the (Mimics) computer. A set of craniometric measurements over these reconstruction images is taken to bring out some skull indexes. This study revealed that that there were statistical differences $(P<0.05)$ among sex related-measurements such as skull length, nasal length, cranial length, skull width, nasal width, cranial width and skull index. Moreover, the rates were compared with other studies in the literature and were brought out the morphologic diversities among species. Specially, it has been thought that the skull indexes recorded in this work can shed light on further craniometric studies.
\end{abstract}

Keywords: 3-dimensional reconstruction, rabbit, skull, craniometry

\section{INTRODUCTION}

Cranium is so important because of having vital anatomik structures belonging to central nervous system [1]. Its biometrical details have to be known well in clinical and surgical applications [2]. Skull morphometry also takes an important part in differentiation of genders. Some indexes of foramen magnum between genders are shown by studies Sukumar et al. [3] and are mentioned about its clinic importance and morphological diversity by Janeczek and Chroszcz [4].

Some craniometric studies are performed on various animal species; Kagani goat (Capra hircus) [1], African Giant Rat [5], Tuj ve Morkaraman Sheep [6], Dog [4], one-humped camels [7], Capreolus, Sheep and Goat [8] with classical methods. There are also craniometrical studies, using computed tomography of German shepherd dog (Alsatian) puppies [9].

Rabbit becomes popular as a pet, in addition to its widely usage in several studies with various purposes. Macroanatomic and morphometric works are performed on rabbit skull $[2,10]$. It is also tried to make standardization in rabbits' craniofacial developing by comparing different measuring methods like flexible plastic ruler, EKG calliper, digital calliper, computed tomography and lateral radiology [11].

In veterinary surgeon, it is seen that craniometric studies are usually performed with classical methods. In anatomic studies with classical methods lots of animals are killed by dissection. The development in computer technology prevents the loss of animals because it enables to form 3D reconstructions from two dimensional computed tomography images. In addition, rotating 3D images in computer provides more easy and reliable measurements [12]. In this way, by morphometric measurements of many animals, the differentness among genders or species can reveal. For example; results of measurements of reconstruction images, differentness among genders of volume and surface areas of paranasal sinuses of New Zealand rabbits, are exhibited with the help of computer technology [13]. 
Some morphological studies on rabbit skull are also executed by dissection without differentiation of gender. This study presents a set of morphometrical measurements for indexes and differentness among genders according to these indexes that belongs to 3D reconstruction of New Zealand rabbits' skull.

\section{MATERials AND MethodS}

The skull-related part of MDCT images were obtained from full screened body of New Zealand rabbits used in a project completed in early 2011 and supported by Coordinatorship of Selçuk University Scientific Research Projects. Also it was accepted by the ethics committee of the Veterinary Faculty of Selçuk University on 24 June 2009 (decition number: 2009/056).

\subsection{Age and Weight}

In this study, a total of 12 New Zealand rabbits of both sexes aged 1-1.5 years and weighing between 3 and $3.5 \mathrm{~kg}$ were used.

\subsection{Anaesthesia}

The rabbits were intravenously anaesthetized with a mixture of $5 \mathrm{mg} / \mathrm{kg}$ ketamine- $\mathrm{HCl}$ (Ketamidor, RicherPharma AG, Austria) and 20 mg/kg propofol (Propofol amp., Fresenius Kabi, Austria).

\subsection{MDCT Images}

Under anesthesia, MDCT images of animals in prone position were obtained. The parameters of MDCT (Somatom Sensation 64, Siemens Medical Solutions, Germany) instrument were adjusted as follows: physical detector collimation, $32 \times 0.6 \mathrm{~mm}$; final section collimation, 64 x $0.6 \mathrm{~mm}$; section thickness, $0.75 \mathrm{~mm}$; gantry rotation period; $330 \mathrm{~ms}$; kVp, 120; mA, 300; resolution, 512 x 512 pixels; resolution range, $0.92 \times 0.92$. Dosage parameters and scanning were performed by predicating them on standard protocols and literature $[14,15]$. Thus, it was tried to obtain radiometric resolution (MONOCHROME2; 16 bit) at the lowest radiation level with optimum image quality. Images of multidedector computed tomography in the head region with high quality are obtained. The axial images obtained were stocked in DICOM format and then evaluated on a personal computer.

Based on the literature [1,2,6,7], following the skull, nasal, cranial and facial lengths, the skull, cranial, nasal, facial and foramen magnum widths, and the foramen magnum height (Figure 1-3) are measured, the skull, cranial, nasal, facial, foramen magnum indexes were calculated. Nomina Anatomica Veterinaria [16] was used in terminology.

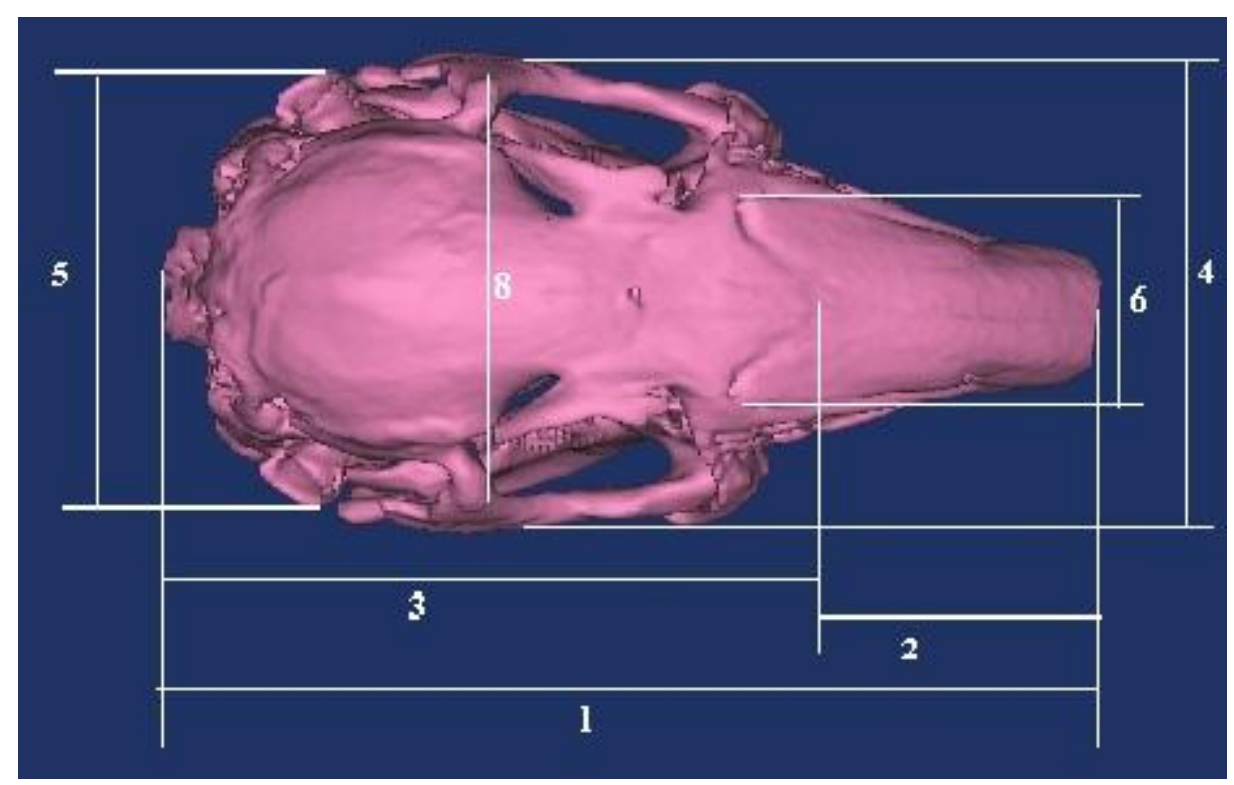

Fig 1. Measurements of 3D reconstruction of New Zealand rabbit skull (dorsal view)

1: Skull length, 2: Nasal length, 3: Cranial length, 4: Skull width, 5: Cranial width,

6: Nasal width, 8: Facial width 


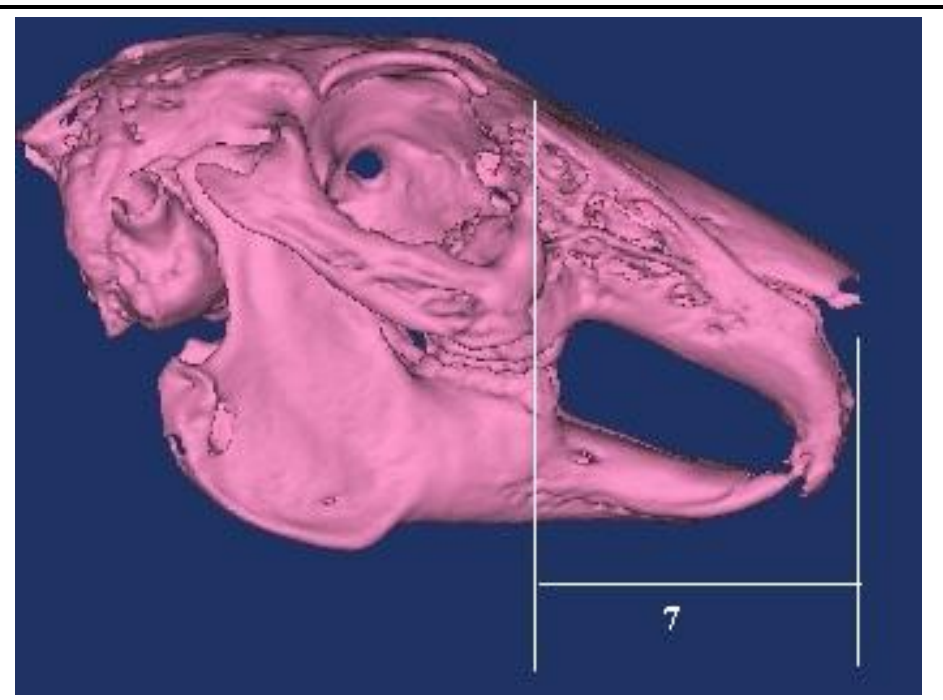

Fig 2. Measurements of $3 D$ reconstruction of New Zealand rabbit skull (lateral view)

$$
\text { 7: Facial length }
$$

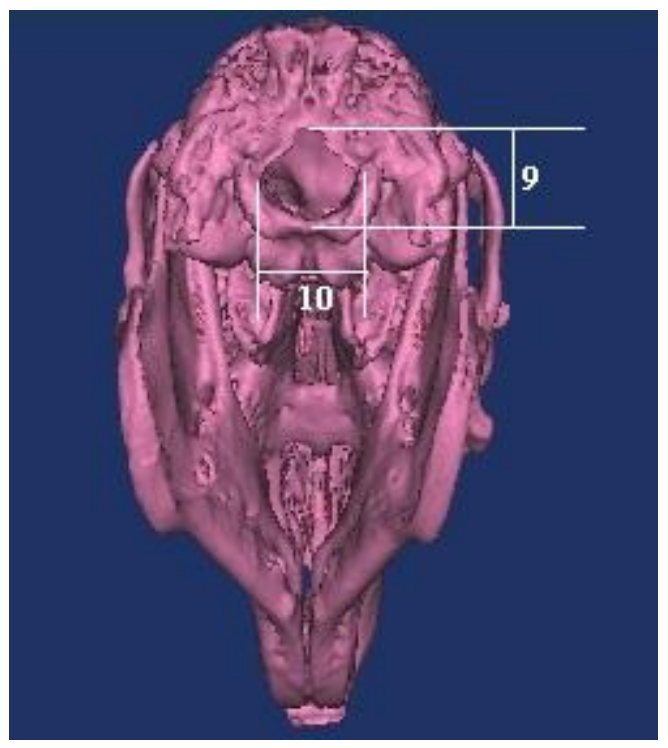

Fig 3. Measurements of $3 D$ reconstruction of New Zealand rabbit skull (caudal view)

$$
\text { 9: Foramen magnum height, 10: Foramen magnum width }
$$

\subsection{Measurements taken from skull}

1. Skull length: From the dorsal lateral nasal cartilages to the external occipital protuberance.

2. Nasal length: Distance from the central point of the frontonasal sutura to the dorsal lateral nasal cartilages.

3. Cranial length: Distance from the central point of the frontonasal sutura to the external occipital protuberance.

4. Skull width: Distance between two zygomatic arches.

5. Cranial width: Distance between two external auditory meatus.

6. Nasal width: Maximum distance across the nasal bones or maximum distance between the naso-maxillary sutures.

7. Facial length: Distance from the frontonasal suture to the centre of the incisive bone.

8. Facial width: Distance between the caudal extents of the orbital rims.

9. Foramen magnum height: The distance between the midpoints of the dorsal ventral rims of the foramen magnum.

10. Foramen magnum width: The maximum distance between the two occipital condyles. 


\subsection{Indexes of skull measurements}

1. Skull index: Skull width/ Skull length $\times 100$

2. Cranial index: Cranial width/ Cranial length $\times 100$

3. Nasal index: Nasal width/ Nasal length $\times 100$

4. Facial index: Facial width/ Facial length $\times 100$

5. Foramen magnum index: Foramen magnum height/Foramen magnum width $\times 100$

\subsection{Statistical Analysis}

The statistical analysis was performed by using SPSS 15.0 for Windows. The independent samples $\mathrm{t}-$ test was carried out and the mean values, deviations and P-values of craniometric measurements and indexes for males and females were calculated. In this study, a statistically significant difference was observed for sexes.

\section{ReSUlts}

3D reconstruction of the New Zealand rabbit skull was performed and craniometric measurements and indexes are statistically analysed. According to statistical results, it was confirmed that the differentness of some craniometric measurements and indexes belongs to male and female rabbits' skull $(\mathrm{P}<0.05)$.

Results from Table 1 show that there are statistically significant differences between skull length, nasal length, cranial length, skull width, cranial width and nasal width of skull of male and female New Zealand rabbits. This measurement value of males was bigger than females. There are no differences between facial length, facial width, foramen magnum height, foramen magnum width of skull of male and female New Zealand rabbits.

Table 1. Statistical results of craniometric measurements of skull of male and female New Zealand rabbits obtained through $3 D$ reconstruction of CT images $(m m \pm S D)$.

\begin{tabular}{|l|c|c|}
\hline Measurements & Male $(\mathbf{n}=\mathbf{6})$ & Female $(\mathbf{n = 6})$ \\
\hline Skull length* & $98,42 \pm 4,15$ & $82,94 \pm 1,65$ \\
\hline Nasal length* & $40,98 \pm 4,73$ & $31,27 \pm 1,67$ \\
\hline Cranial length* & $57,44 \pm 9,92$ & $51,67 \pm 0,87$ \\
\hline Skull width* & $40,54 \pm 1,17$ & $38,01 \pm 0,57$ \\
\hline Cranial width* & $39,52 \pm 2,10$ & $35,99 \pm 0,59$ \\
\hline Nasal width* & $20,54 \pm 1,64$ & $17,21 \pm 1,09$ \\
\hline Facial length & $36,33 \pm 7,50$ & $31,06 \pm 6,19$ \\
\hline Facial width & $40,23 \pm 2,18$ & $37,81 \pm 1,77$ \\
\hline Foramen magnum height & $11,92 \pm 1,12$ & $11,87 \pm 0,99$ \\
\hline Foramen magnum width & $13,27 \pm 1,00$ & $13,26 \pm 0,74$ \\
\hline
\end{tabular}

*: $\mathrm{P}<0.05$. Data expressed as the mean $\pm \mathrm{SD}$

Results from Table 2 show that there are statistically significant differences between skull indexes of skull of male and female New Zealand rabbits. Female rabbits' skull index is bigger than males. There are no differences between Cranial index, nasal index, facial index, foramen magnum index of skull of male and female New Zealand rabbits.

Table 2. Statistical results of indexes of skull of male and female New Zealand rabbits obtained through 3D reconstruction of CT images $(\% \pm S D)$.

\begin{tabular}{|l|c|c|}
\hline Measurements & Male $(\mathbf{n}=\mathbf{6})$ & Female $(\mathbf{n = 6})$ \\
\hline Skull index* & $41,23 \pm 1,79$ & $45,83 \pm 1,00$ \\
\hline Cranial index & $68,84 \pm 2,99$ & $69,67 \pm 1,74$ \\
\hline Nasal index & $50,44 \pm 4,56$ & $55,10 \pm 3,60$ \\
\hline Facial index & $115,22 \pm 26,82$ & $125,92 \pm 25,49$ \\
\hline Foramen magnum index & $89,87 \pm 7,92$ & $90,13 \pm 5,92$ \\
\hline
\end{tabular}

$*: \mathrm{P}<0.05$. Data expressed as the mean $\pm \mathrm{SD}$ 


\section{DISCUSSION}

New Zealand rabbits' skull length, nasal length, cranial length, cranial width that were obtained in this study are matched with the digital caliper measurement's results of rabbits' skull, which were performed by Monfared [2] without looking at their genders. Monfared [2] identified skull length; $9,41 \mathrm{~cm}$, nasal length $3,29 \mathrm{~cm}$, cranial length; $6,11 \mathrm{~cm}$, cranial width; $3,29 \mathrm{~cm}$. In our study, it was measured skull length: $98,42 \mathrm{~mm}$; nasal length: $40,98 \mathrm{~mm}$; cranial length: $57,44 \mathrm{~mm}$; cranial width: $39,52 \mathrm{~mm}$ in males; but in females skull length: $82,94 \mathrm{~mm}$; nasal length: $31,27 \mathrm{~mm}$; cranial length: $51,67 \mathrm{~mm}$; cranial width: $35,99 \mathrm{~mm}$. This shows us that the 3D reconstruction measurement rates totally reflect the truth. Abreu et al. [11] reached different rates in craniofacial measurement, which he practiced different morphometric methods like flexible plastic ruler, EKG caliper, digital caliper, computed tomography and lateral radiology. This prevents to reach any standard results in rabbit cranium. The milimetric measurements that were taken from 3D images via computer programme are reliable.

There are statistical differentness between gender in skull length, nasal length, cranial length, skull width, nasal width and skull index, but there is no differentness among these measurements between African giant rat's males and females. According to this, craniometric measurement can be changeable between different species' genders [5].

It was not observed any statistical differentness in foramen magnum diameters between male and female New Zealand rabbits. Moreover, Yahaya et al. [7] identified that there is no difference in foramen magnum's caliper between one-humped camel genders. Nonetheless Sukumer et al. [3] identified statistically that South Indians' foramen magnum has differences between genders. Foramen magnum's diameter is bigger in males than females. Moreover, Olude et al. [5] identified that African giant rat's foramen magnum width rates are statistically different between genders.

New Zealand rabbits' foramen magnum width (males: 13,27 mm; females: 13,26 mm) are more than their height (males: 11,92 mm; females: 11,87). Foramen magnum index is 89,97 in males and 90,13 in females. One-humped camel foramen magnum height (males: $3,32 \mathrm{~cm}$; females: $3,27 \mathrm{~cm}$ ) has more rate than width (males: $3,23 \mathrm{~cm}$; females $3,13 \mathrm{~cm}$ ). Foramen magnum index is 102,83 in males and 104,33 in females [7]. This shows us that New Zealand rabbits' foramen magnum shapes as ellipsis in horizontal plane, one-humped camel foramen magnum shape as ellipsis in vertical plane. We can easily say that foramen magnum takes different shapes among species apart from these animals.

Consequently, 3D reconstructions of New Zealand rabbits' cranium were performed, several craniometric measurement rates were taken and the differences between genders were found out by indexes. Besides, these rates were compared with other studies in literature and the morphologic differences between genders were revealed. Specially, it is thought that this study can enlighten other studies about biometric measurements of rabbit skull, using in anesthesia studies.

\section{REFERENCES}

[1]. Sarma, K. Morphological and craniometrical studies on the skull of Kagani goat (Capra hircus) of Jammu region. Int J Morphol, 24: 449-455, (2006).

[2]. Monfared, A.L. Applied anatomy of the rabbit's skull and its clinical application during regional anesthesia. Global Vet, 10: 653-657, (2013).

[3]. Sukumar, S., Yadav, S., Manju, H.B. 3D Reconstruction computer tomography of foramen magnum and fronto nasal junction for sex determination in South Indian Population. Int J Pharm Bio Sci, 3: 615- 619, (2012).

[4]. Janeczek, M., Chroszcz, A. The occipital area in medieval dogs and the role of occipital dysplasia in dog breeding. Turk. J Vet Anim Sci, 35: 453-458 (2011).

[5]. Olude, M.A., Olapade, J.O., Fatola, I.O., Onwuka, SK. Some aspects of the neurocraniometry of the African giant rat (Cricetomys gambianus Waterhouse). Folia Morphol, 68: 224-227, (2009).

[6]. Özcan, S., Aksoy, G., Kürtül, İ., Aslan, K., Özüdoğru, Z. A comparative morphometric study on the skull of the Tuj and Morkaraman sheep. Kafkas Univ Vet Fak Derg, 16: 111-114, (2010).

[7]. Yahaya, A., Olopade, J.O., Kwari, H.D., Wiam, I.M. Osteometry of the skull of one-humped camels. Part I: immature animals. IJAE, 117: 23-33, (2012). 
[8]. Onuk, B., Kabak, M., Atalar, K. Anatomic and craniometric factors in differentiating roe deer (Capreolus capreolus) from sheep (Ovis aries) and goat (Capra hircus) skulls. Arch Biol Sci, 65: 133-141, (2013).

[9]. Onar, V., Kahvecioğlu, O., Çebi, V. Computed tomographic analysis of the cranial cavity and neurocranium in the German shepherd dog (Alsatian) puppies. Vet Arhiv, 72: 57-66, (2002).

[10].Farag, F.M., Daghash, S.M., Mohamed, E.F., Hussein, M.M., Hagrass, S.M. Anatomical studies on the skull of the domestic rabbit (Oryctolagus cuniculus) with special reference to the hyoid apparatus. J Vet Anat, 5: 49-70, (2012).

[11]. Abreu, A.T., Veek, E.B., Costa, N.P. Morphometric methods to evaluate craniofacial growth: study in rabbits. Dentomaxillofac Rad, 35: 83-87, (2006).

[12]. Özkadif, S., Eken, E. Modernization process in veterinary anatomy education. Energy Educ Sci Technol-Pt B, 4: 957-962, (2012).

[13]. Özkadif, S., Eken, E. Three-dimensional reconstruction of multidetector computed tomography images of paranasal sinuses of New Zealand rabbits. Turk J Vet Anim Sci, 37: 675- 681, (2013).

[14].Kalra, M.K., Maher, M.M., Toth, T.L., Hamberg, L.M., Blake, M.A., Shepard, J., Saini, S. Strategies for CT radiation dose optimization. Radiology, 230: 619-28 (2004).

[15]. Prokop, M. General principles of MDCT. Eur J Radiol,45: 4-10, (2003)

[16]. International Committee on Veterinary Gross Anatomical Nomenclature. Nomina Anatomica Veterinaria (N.A.V.). 5th ed. World Association of Veterinary Anatomists, Hannover, Columbia, Ghent, Sapporo, (2012).

\title{
AUTHORS' BIOGRAPHY
}

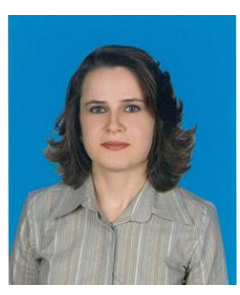

\author{
Assist. Prof. Dr. Sema ÖZKADİF \\ Batman University, School of Health, \\ Department of Nursing, Batman/ Turkey
}

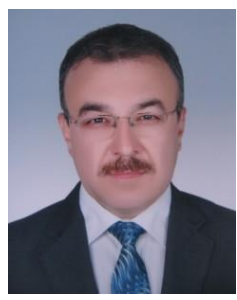

\section{Prof. Dr. Emrullah EKEN}

Selçuk University, Faculty of Veterinary Medicine,

Department of Anatomy, Konya/ Turkey 